\title{
THERMAL EFFECTS IN TRANSFORMATIONS IN METALS
}

"T "HERMAL Effects in Transformations in Metals" was the title of a lecture delivered on May 13 by Dr. C. Sykes, superintendent of the Metallurgy Department, National Physical Laboratory, to the London and Home Counties' Branch of the Institute of Physics in the lecture hall of Messrs. Kodak Ltd., Harrow.

Dr. Sykes instanced the change which occurs during the cooling of eutectoid steel as a familiar and typical phase transformation. This transformation from face-centred $\gamma$-iron to body-centred $\alpha$-iron and iron carbide $\left(\mathrm{Fe}_{3}(\mathrm{y})\right.$ has formed the subject of many investigations, and its suitable control has led to important variations being realized in the properties of steel. The temperature at which a transformation takes place has usually been determined from observations on either the direct cooling curve or the inverse-rate curve, or is deduced from the microstructures of samples which have been quenched or slowly cooled from various temperatures. In recent years the limitations of these methods have become apparent. The furnace-cooling methods clearly define the temperature at which a transformation commences, for there the energy released within the specimen causes a definite change in its rate of cooling. This change in rate has but little effect on the cooling of the more massive furnace, and the resultant variation in the difference in tem. perature between the furnace and the specimen affects the rate of cooling of the latter, so that great care is needed in the interpretation of subsequent results. In the case of $\beta$-brass a transformation occurs which commences at about $460^{\circ} \mathrm{C}$. and continues down to about $160^{\circ} \mathrm{C}$. Transformations of this type require entirely new methods of thermal analysis. Furthermore, since the change consists merely of a rearrangement of the atoms within the solid solution, an examination of the microstructure is no longer helpful.

Little progress was made in the study of such transformations until Tammann observed that they nearly always occur with binary alloys of the types $X Y$ and $X_{3} Y$. For the body-centred cubic crystal $\mathrm{CuZn}$ ( $\beta$-brass), he suggested that, whereas at high temperatures the atoms are randomly arranged, at low temperatures the copper and zinc atoms are each on separate lattices. Thus, on cooling, heat will be evolved as the atoms settle into the more orderly arrangement. The theory of an ordering process based on similar assumptions to those of Tammann has been worked out by Bragg and Williams. They introduced the quantity $s$ to represent the degree of order of the alloy, and postulate that $s=1$ corresponds to perfect order and $s=0$ to complete disorder, that is, the random arrangement. For an $X Y$ alloy such as CuZn, it is shown that $s$ can be represented by $\tanh (V / 4 k T)$, where $\mathrm{V}$, the energy required to interchange a $\mathrm{Cu}$ and $\mathrm{Zn}$ atom, is not constant but equal to $s V_{0}$. These equations have been solved for $s$ as a function of $T$.

There is shown to be a definite critical temperature, $T_{c}$, where the value of $s$ commences to rise steeply from zero and to tend asymptotically to unity at a lower temperature. The $X_{3} Y$ alloy differs in that $s$ rises from zero to a finite value at $T_{c}$ and then shows a similar increase towards unity at lower temperatures. It is possible to calculate the energy changes associated with these transformations and so to predict the variation of specific heat with temperature. The transformation should cause the specific heat to exceed the normal value, to rise to a sharp maximum at $T_{c}$, and then fall back on to the normal curve. With an alloy of the $X_{3} Y$ type there should be a definite latent heat at $T_{c}$. In the Bragg-Williams theory the average degree of order in the whole crystal has been considered, and a slightly modified result has been obtained by Bethe, who defines order from considerations of the nature of the neighbouring atoms around a given atom of either kind in the structure. Bethe's theory predicts that although superlattice order disappears at the critical tem. perature, a high degree of local order persists, giving an abnormally high specific heat, which only vanishes at very high temperatures.

At this stage the need for more precise methods for the determination of specific heats over wide ranges of temperature became imperative, and Dr. Sykes was responsible for the development of a method which proved highly satisfactory. The specimen, in the form of a small cylinder fitted with an internal heating coil, is mounted inside a cylindrical copper block from which it is thermally insulated. The whole is inserted in a furnace and can be evacuated. Now suppose the furnace is so controlled that the temperature of the copper block increases at a constant rate, then the temperature of the specimen will rise along a lower curve. If, however, energy is generated in the coil within the specimen, it is possible to bring the temperature of the latter above that of the furnace. At the instant at which their temperatures are the same, no external heat is received by the specimen and so $Q=M C_{p}(d T / d t)$, where $Q$ is the power supplied to the specimen, $C_{p}$ its instantaneous specific heat and $d T / d t$ the rate of temperature rise of the specimen. By suitable manipulation of $Q$, the temperatures of specimen and furnace can frequently be brought into equality and a series of determinations of $C_{p}$ can be made at increasing temperatures.

Much skill and ingenuity has been used in the development of the apparatus, and the accuracy obtainable is \pm 1 per cent at $400^{\circ} \mathrm{C}$. and \pm 2 per cent at $600^{\circ} \mathrm{C}$. It has been possible to ensure that the temperature of the specimen does not depart from that of the block by more than $0 \cdot 1^{\circ} \mathrm{C}$. Under these conditions the experiment can be modified to give the total heat content for a specified range of temperature. When this is done, the specimen heater current is passed through a copper voltameter so as to obtain an integrated value of the power supplied.

Detailed experimental results were described for two alloys, CuZn and $\mathrm{Cu}_{3} \mathrm{Au}$. For $\mathrm{CuZn}$ the total energy associated with the ordering transformation was found to be $9.8 \mathrm{cal}$./gm., whereas the BraggWilliams theory gave 11.4 and the Bethe theory $10.8 \mathrm{cal} / \mathrm{gm}$. Above the critical temperature the specific heat remains abnormally high, owing presumably to the presence of local order.

Further confirmation that $\beta$-brass undergoes an order-disorder transformation has been obtained from 
X-ray spectrographs. Extra lines, the so-called superlattice lines, have been observed in X-ray photographs of the ordered structure taken with zine radiation.

$\mathrm{Cu}_{3} \mathrm{Au}$ has a face-centred lattice with gold atoms at the corners of each cube and copper atoms at the centre of each face. In this instance it is easy to establish the existence of a superlattice by means of $\mathrm{X}$-ray analysis ; in fact, an idea of the completeness of the ordering can be formed from an examination of the intensities of the superlattice lines. The thermal measurements, on the other hand, are somewhat more complicated owing to the slowness with which equilibrium is attained. To overcome this difficulty the following technique had to be adopted. From $420^{\circ} \mathrm{C}$. upwards it was found that the specific heat curve was independent of the initial state of the alloy, so presumably it was always in equilibrium at this temperature. The effect of temperature on the energy content was therefore obtained by annealing a specimen at a temperature $T$ until equilibrium was attained and then measuring the energy necessary to heat the alloy from $T$ to $420^{\circ} \mathrm{C}$. Since the specimen is in equilibrium both at the beginning and end of the experiment, the energy input to the specimen heater is equal to the difference in equilibrium energy contents corresponding to the initial and final temperatures, although at intermediate temperatures the alloy need not be in equilibrium. The anticipated latent heat is observed and the general agreement with theory is reasonably good, although neither theory gives a correct representation of the release of energy near the critical temperature. The Bragg-Williams theory gives a curve rising too slowly with decreasing temperature, and Peierls's (who has applied Bethe's theory to this alloy) theory gives too great a latent heat.

Other alloys which have been examined are $\mathrm{Cu}_{3} \mathrm{Pd}$ and $\mathrm{Ni}_{3} \mathrm{Fe}$, and in both cases fairly good agreement with theory has resulted. $\mathrm{Ni}_{3} \mathrm{Fe}$, which closely resembles mumetal, is of interest in that it has been found that the best magnetic properties are obtained when the-alloy is in a state of partial order.

The development of these precise methods of thermal analysis are thus seen to have done much to remove the difficulties which metallurgists have encountered in dealing with order-disorder transformations.

R. W. POWELL.

\section{EFFECT OF THE WAR ON BIRD LIFE}

\section{By R. S. R. FitTER \\ Recorder of the Ornithological Section, London Natural History Society}

\begin{abstract}
VERY little is yet known about the effect of the War on bird life in Britain, though the secretary of the British Trust for Ornithology has appealed for information on the subject. It is easy enough to make a number of theoretical deductions from the known variations in ecological and other factors. The decrease of gamekeepers' activity should result in an increase of hawks and owls ; the increase of arable and decrease of pasture land is bound to affect the balance of Nature in various ways; the felling of many woodlands will certainly make the woodland birds scarcer after the War; the reduction in the number of oil-discharging boats frequenting the British seas should result in a smaller death-rate among sea-birds ; and so on.
\end{abstract}

A good many scattered records about the actual effect of the War on bird life have appeared in various journals, and should be collated. The present article is based on records sent in to the London Natural History Society during the past year.

Actual casualties among birds appear fortunately to have been very few. A research-worker in the north of England wrote asking to be sent the corpses of any starlings that might be found lying about London after a night of air raid, but though the starlings still come in to roost in London every night, I have not heard of any being killed in an air raid, though doubtless a "large number have been. The only definite casualty reported is a missel-thrush killed by a bomb explosion in Hertfordshire. It was found dead thirty yards from where the bomb burst, and there was a wooden fence in between.

Several records have come in of birds taking fright at day-time bomb explosions. The explosion of delayed-action bombs in one area sent a heron screaming over a neighbouring garden, and on another occasion eight crows flew over after a similar explosion. From the same area comes a report that heavy gunfire sends the gulls home to roost early. A barn-owl, on the other hand, has been reported sereeching during an anti-aircraft barrage, while a swift was seen eircling around quite unperturbed by an air battle going on overhead. A green sandpiper, too, was not driven from its customary roosting-place by the fact that three bombs fell in a neighbouring field, while in two heronries numbers breeding in 1941 were undiminished in spite of many bombs falling in unpleasantly close proximity. Once a wheatear was seen flitting about over the wreckage in one of the worst devastated areas of the East End.

House-sparrows, too, have shown their enterprise. In one suburban town they were quick to explore the new nooks and crannies in a bombed house, and showed a marked partiality for new putty, possibly because of the linseed oil it contained. One result of the bombing of London has been to provide an abundance of potential nesting sites for the black redstarts, which are showing a tendeney to colonize London. So far, however, the birds which have appeared in 1941 have favoured only Westminster Abbey, where they bred last year, and the British Museum (Natural History) in South Kensington, where they have been reported in several previous years.

Not many effects of the War on birds' feeding habits were reported, but a large number of blackheaded gulls, together with several great and lesser black-backed gulls and carrion crows were seen feasting on the fish apparently killed by bombs falling in the Thames. When two small lakes were drained, black-headed gulls came and cleared the mud of mussels.

The activities of soldiers have had a detrimental effect on bird life in at least one area, where smaller numbers of redstarts and whitethroats are reported to have nested, as a result of military operations, and a cock whinchat disappeared after being alarmed by 